\title{
Drugs, bugs, and MS
}

\section{The interplay between disease-modifying therapy and gut microbiota}

Ashutosh K. Mangalam, PhD

Neurol Neuroimmunol Neuroinflamm 2019;6:e524. doi:10.1212/NXI.0000000000000524

MS is an inflammatory disease in which both genetic and environmental factors play roles in the predisposition to disease. A number of recent studies suggest that gut microbiota might be a potential environmental factor linked with the pathogenesis of MS. Trillions of bacteria residing in the human gut (gut microbiota) play an important role in maintaining a healthy state, and perturbation of the gut microbiota is associated with exacerbation and/or precipitation of MS. A number of recent studies have shown that patients with MS have gut dysbiosis characterized by altered levels of certain gut bacteria. ${ }^{1-5}$ Because MS is an inflammatory disease, it is hypothesized that gut bacteria enriched in patients with MS might possess proinflammatory properties, whereas those showing reduced relative abundance might be anti-inflammatory in nature.

Initial MS microbiome studies may be confounded because of disease-modifying therapies (DMTs). Hence, it is important to delineate the role of gut microbiota changes specific to disease from those influenced by DMTs. In this issue of Neurology ${ }^{\circledR}$ : Neuroimmunology \& Neuroinflammation, Katz Sand et al. ${ }^{6}$ analyzed gut microbiota profile in patients with relapsingremitting MS (RRMS). They conducted a cross-sectional study to determine the effect of 2 commonly used DMTs, dimethyl fumarate (DMF) and glatiramer acetate (GA), on gut microbiota composition in patients with RRMS. The authors recruited 75 treatment-naive RRMS patients, 33 patients with RRMS on DMF, and 60 patients with RRMS on GA at 2 different MS centers, 1 in New York, NY and another in San Francisco, CA. Although samples were collected from 2 different geographical locations, no community-level differences were detected, indicating that there was no significant effect on gut microbiota because of geography. DMF and GA treatment also had no effect on microbial richness ( $\alpha$-diversity) or bacterial community diversity ( $\beta$-diversity), which suggests that DMTs had no major impact on overall gut microbiota composition. However, taxa-level analyses using linear discriminant analysis effect size (LEfSe) showed certain bacterial genera with increased or decreased relative abundance in DMT-treated RRMS patients compared with the treatment naive RRMS group. The DMF-treated group showed reduced relative abundance of the order Clostridiales and families Lachnospiraceae, Veillonellaceae, and Tissierellaceae. As certain species from the order Clostridiales had been linked with MS and neuromyelitis optica, it is suggested that DMTs might act through suppressing proinflammatory bacteria belonging to the order Clostridiales. However, the order Clostridiales also contains a number of bacteria with anti-inflammatory properties, especially bacteria with ability to induce $\mathrm{CD}^{+}{ }^{+} \mathrm{FoxP}^{+}$regulatory $\mathrm{T}$ cells (Tregs). ${ }^{7}$ Levels of Bacteroides also trended higher in the DMT-treated RRMS group, which contain bacteria such as Bacteroides fragilis with the ability to induce Tregs and suppress disease in experimental model of MS. ${ }^{8}$ Recent studies have shown that DMT treatment is associated with an increased relative abundance of Prevotella and Sutterella genera. ${ }^{3,9}$ However, the current study failed to find an increase in relative abundance of either Prevotella or Sutterella. The authors suggest that induction of Prevotella and Sutterella in other studies may be due to interferon beta (IFN $\beta$ ) because patients with RRMS in those other studies were treated with IFN $\beta$ alone or IFN $\beta /$ GA. Thus, the jury is still out regarding the link between GA or DMF treatment and Prevotella and/or Sutterella.

\author{
Correspondence \\ Dr. Mangalam \\ Ashutosh-mangalam@uiowa.edu
}

\section{RELATED ARTICLE}

Disease-modifying therapies alter gut microbial composition in MS 
Analysis of functional pathways using phylogenetic investigation of communities by reconstruction of unobserved states showed modulation of retinol (Vitamin A) metabolism in both DMF- and GA-treated groups. Because retinoic acid metabolism is linked with generation of Tregs by dendritic cells in the small intestine, it is possible that the beneficial effects of GA and DMF are through modulation of immune responses toward anti-inflammatory activity by inducing regulatory CD4 $\mathrm{T}$ cells (Tregs) in the gut. However, identification of metabolic pathways using either shotgun metagenomic sequencing or fecal metabolite measurements needs to be performed to validate the role of retinol metabolism in the beneficial effects of GA and DMF in patients with MS.

This study by Sand Katz et al. ${ }^{6}$ is an important first step in understanding the interplay between DMTs, gut microbiota, and MS microbiome. Their data suggest that certain bacteria belonging to a specific taxa, especially those belonging to the order Clostridiales, may play important roles in disease pathogenesis. However, in the absence of bacterial classification at the genera or species level, it is difficult to identify the specific bacterial species responsible for the beneficial effect of DMTs. This study used $150 \mathrm{bp}$ paired-end sequencing, which might not achieve resolution comparable to the newer 250 or $300 \mathrm{bp}$ paired-end reads. In addition, the microbiome field is moving away from operational taxonomic unit (OTU)-based gut microbiota profiling to amplicon sequence variants (ASVs) because ASVs can identify bacteria at the genus or even at the species level. ${ }^{10}$ Thus, future studies using longer paired-end reads and identifying bacterial species (ASVs) using the Divisive Amplicon Denoising Algorithm-2 (DADA-2) platform will be more informative. In the absence of a predisease group and/or healthy control group, it is difficult to conclude whether treatment with DMTs restored the gut microbiota toward a healthy microbiome or predisease state.

In conclusion, this finding suggests that DMTs might lead to subtle changes in the composition of gut microbiota and highlight its significance in MS. However, multicentric longitudinal studies will validate and authenticate the role of gut microbiota in MS. Further studies are also needed to determine whether gut dysbiosis precedes MS or it is a consequence of disease, treatment, or other unknown factors. The current study by Katz Sand et al. and previous 2 studies have laid the groundwork for future studies to determine the role of gut microbiome in the pathogenesis of MS.

\section{Study funding}

No targeted funding reported.

\section{Disclosure}

A. Mangalam receives research support from the NIH (R01AI137075); holds a patent on Use of Prevotella histicola for treatment of autoimmune condition (Licensed to Evelo Biosciences); and receives royalties from Mayo Clinic (paid by Evelo Biosciences). Full disclosure form information provided by the authors is available with the full text of this article at Neurology.org/NN.

\section{References}

1. Miyake S, Kim S, Suda W, et al. Dysbiosis in the gut microbiota of patients with multiple sclerosis, with a striking depletion of species belonging to Clostridia XIVa and IV Clusters. PLoS One 2015;10:e0137429.

2. Chen J, Chia N, Kalari KR, et al. Multiple sclerosis patients have a distinct gut microbiota compared to healthy controls. Sci Rep 2016;6:28484.

3. Jangi S, Gandhi R, Cox LM, et al. Alterations of the human gut microbiome in multiple sclerosis. Nat Commun 2016;7:12015.

4. Berer K, Gerdes LA, Cekanaviciute E, et al. Gut microbiota from multiple sclerosis patients enables spontaneous autoimmune encephalomyelitis in mice. Proc Natl Acad Sci U S A 2017;114:10719-10724.

5. Cekanaviciute E, Yoo BB, Runia TF, et al. Gut bacteria from multiple sclerosis patients modulate human T cells and exacerbate symptoms in mouse models. Proc Natl Acad Sci U S A 2017;114:10713-10718.

6. Katz Sand I, Zhu Y, Ntranos A, et al. Disease-modifying therapies alter gut microbial composition in multiple sclerosis. Neurol Neuroimmunology Neuroinflammation 2018;6:e517. doi: 10.1212/NXI.0000000000000517.

7. Atarashi $\mathrm{K}$, Tanoue $\mathrm{T}$, Oshima $\mathrm{K}$, et al. Treg induction by a rationally selected mixture of Clostridia strains from the human microbiota. Nature 2013;500:232-236.

8. Ochoa-Reparaz J, Mielcarz DW, Wang Y, et al. A polysaccharide from the human commensal Bacteroides fragilis protects against CNS demyelinating disease. Mucosal Immunol 2010;3:487-495.

9. Castillo-Alvarez F, Perez-Matute P, Oteo JA, Marzo-Sola ME. The influence of in terferon beta- $1 \mathrm{~b}$ on gut microbiota composition in patients with multiple sclerosis [in Spanish]. Neurologia Epub 2018 Jun 9.

10. Callahan BJ, McMurdie PJ, Holmes SP. Exact sequence variants should replace operational taxonomic units in marker-gene data analysis. ISME J 2017;11:2639-2643. 


\title{
Neurology \\ Neuroimmunology \& Neuroinflammation
}

\author{
Drugs, bugs, and MS: The interplay between disease-modifying therapy and gut \\ microbiota \\ Ashutosh K. Mangalam \\ Neurol Neuroimmunol Neuroinflamm 2019;6; \\ DOI 10.1212/NXI.0000000000000524
}

This information is current as of November 27, 2018

\section{Updated Information \& \\ Services}

References

Subspecialty Collections

Permissions \& Licensing

Reprints including high resolution figures, can be found at:

http://nn.neurology.org/content/6/1/e524.full.html

This article cites 9 articles, 2 of which you can access for free at: http://nn.neurology.org/content/6/1/e524.full.html\#\#ref-list-1

This article, along with others on similar topics, appears in the following collection(s):

All Demyelinating disease (CNS)

http://nn.neurology.org//cgi/collection/all_demyelinating_disease_cns

All Immunology

http://nn.neurology.org//cgi/collection/all_immunology

Multiple sclerosis

http://nn.neurology.org//cgi/collection/multiple_sclerosis

Information about reproducing this article in parts (figures,tables) or in its entirety can be found online at:

http://nn.neurology.org/misc/about.xhtml\#permissions

Information about ordering reprints can be found online:

http://nn.neurology.org/misc/addir.xhtml\#reprintsus

Neurol Neuroimmunol Neuroinflamm is an official journal of the American Academy of Neurology.

Published since April 2014, it is an open-access, online-only, continuous publication journal. Copyright

Copyright $\odot 2018$ The Author(s). Published by Wolters Kluwer Health, Inc. on behalf of the American

Academy of Neurology.. All rights reserved. Online ISSN: 2332-7812.

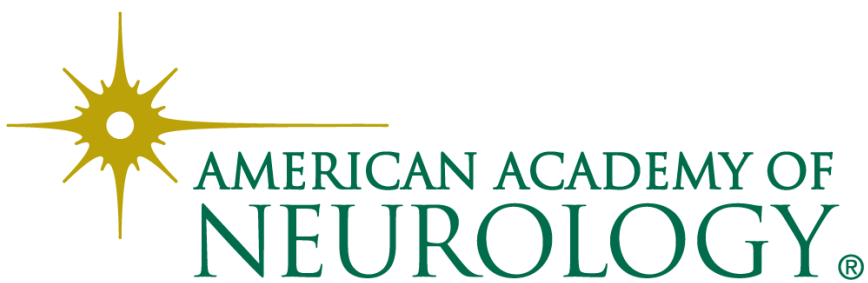

